\title{
Centaurea cheirolopha (Fenzl) Wagenitz ve Centaurea lycopifolia Boiss. \& Kotschy (Asteraceae) Taksonlarının Anatomik ve Mikromorfolojik Karakterlerinin İncelenmesi
}

\author{
Rahim AYDIN ${ }^{(1)}$, Hüseyin DURAL ${ }^{(D)}$, Burcu YILMAZ ÇITAK (D)
}

Selçuk Üniversitesi, Fen Fakültesi, Biyoloji Bölümü, Konya

Geliş / Received: 22.01.2019, Kabul / Accepted: 15.12.2019

\section{$\ddot{O} z$}

$\mathrm{Bu}$ araştırma ile Türkiye'de yayılış gösteren Centaurea cinsine ait morfolojik olarak birbirine oldukça yakın karakterlere sahip $C$. lycopifolia ve $C$. cheirolopha taksonlarının anatomik, palinolojik ve aken mikromorfolojik özellikleri ayrıntılı olarak ortaya konulmuştur. Anatomik araştırmalar, parafin yöntemi ya da el ile alınan kesitlerin kullanılmasıyla gerçekleştirilmiştir. Türlerin anatomik yapılarında, kök korteksinde $C$. cheirolopha'nın sklerenkimatik hücreler ihtiva etmesi ile iki türün birbirinden farklılık gösterdiği gözlenmiştir. Gövdelerden alınan enine kesitler, tipik dikotiledon anatomik yapısını yansıtmış olup, türlerin silindirik yapıda korteks tabakası ile kollenkimatik hücreler ihtiva ettiği tespit edilmiştir. Gövdedeki iletim demetlerinin sıra sayısı C. lycopifolia'da iki iken, C. cheirolopha'da tektir. Yaprak anatomisinde mezofil dokusu her iki takson içinde ekvifasiyal olarak tespit edilmiştir. Midripteki iletim demet sayısı yine türler arasında farkl1l1k göstermekte olup, C. cheirolopha'da üç, C. lycopifolia'da tektir. İncelenen türler, monad, izopolar, prolat-sferoidal ve trikolporat polen tanelerine sahiptir. Her iki takson için ekzin skülptürü skabratperforat olarak gözlenmiştir. Araştırılan taksonların her ikisi de kahverengi-saman renkli akenlere sahip fakat C. cheirolopha'da belirgin krem çizgiler mevcuttur. Pappustaki kılçık şekillerinin taksonlar arasında açık şekilde farkl1lık gösterdiği gözlemlenmiştir. Sonuç olarak, C. lycopifolia ve C. cheirolopha taksonlarının anatomik, palinolojik ve mikromorfolojik karakterlerinin taksonların ayrımına destek sağladığı ortaya konulmuştur.

Anahtar Kelimeler: Anatomi, Centaurea, Compositae, SEM.

\section{Investigation of Morphological, Anatomical and Micromorphological Characteristics of Centaurea cheirolopha (Fenzl) Wagenitz and Centaurea lycopifolia Boiss. \& Kotschy (Asteraceae) Taxa}

\begin{abstract}
With this study, $C$. lycopifolia and $C$. cheirolopha which are close species with their anatomical, palynological and achene micro morphological traits were presented in detail. The anatomical researches have been carried out by paraffin method or using handmade sections. In the anatomical structures of taxa, it was observed that $C$. cheirolopha contains sclerenchymatic cells and that two species differed from each other. The cross sections taken from stems were reflected the typical dicotyledonous stem anatomical structure and were determined that species have cortex parenchyma with cylindrical shaped and collenchymatic cells. The rows of vascular bundles in stem are two in C. lycopifolia as one in C. cheirolopha. Mesophyll were detected as equifacial in both species in leaves. The numbers of vascular bundles in midrib are variable between studied species and were three in C. cheirolopha and one in C. lycopifolia. The studied taxa have monad, isopolar, prolate-spheroidal and tricolporate pollen grains. For two examined species, exine sculpture were observed as scabrate-perforate. Both of examined species have brown-straw color achene but C. cheirolopha has also distinct cream lines. The shapes of pappus of spines were observed distinctly different in species. As a conclusion, the characteristics of anatomical, palynological and micro morphological in C. lycopifolia and C. cheirolopha have been revealed supporting the separation of species.
\end{abstract}


Keywords: Anatomy, Centaurea, Compositae, SEM.

\section{Giriş}

Asteraceae familyası, Antartika kıtası hariç dünyaya yayılmış 1600-1700 cinsi içermektedir. 250,000-350,000 arasında çiçekli bitkinin bulunduğunu varsayarsak, her sekiz ile on iki türden biri Asteraceae içerisinde yer almaktadır (yaklaşık \%10).

Türkiye Florası için önemli ve oldukça büyük bir cins olan Centaurea L., özellikle Iran-Turan ve Akdeniz bölgelerinde olmak üzere Avrasya'da yayılış gösteren yaklaşık 250 türden oluşmaktadır (Anderberg ve Elden, 2007). Türkiye'de, 181 toplam türün 112 'si, 32 alttürün 18 'i, 28 varyetenin 16'sının endemik olması ile Centaurea cinsi en yüksek endemizm oranına sahip cinslerden birisidir (Uysal, 2012). Türkiye Bitki Listesi yayımlandıktan sonra yeni türlerin eklenmesiyle toplam tür sayısı 200'e ulaşmıştır (Bona 2015; Yüzbaşığlu vd., 2015; Kültür vd, 2016; Uysal vd., 2016; Uysal ve Hamzaoğlu, 2017; Uysal vd., 2017; Behçet vd., 2017; Armağan ve Uysal, 2018). Cinsin endemizm oran1 \% 58 olarak belirlenmiştir.

Centaurea cinsi bitkinin sistematik özellkleri dişında biyokimyasal, antimikrobiyal, antiinflamatuvar, antioksidant, antihipertensif, sitotoksisite gibi birçok çalışmaya da konu olmuştur (Garbacki vd., 1999; Köse vd., 2016; Escher vd., 2018). C. cehirolopha ve C. lycopifolia taksonlarının antimikrobiyal aktivitesi belirlenmiştir (Köse vd., 2016).

C. cheirolopha ve C. lycopifolia taksonları birbirlerine morfolojik olarak oldukça benzeyen iki taksondur. C. lycopifolia türünün tehlike kategorisi LR olarak belirlenmiş iken, C. cheirolopha taksonuna ait tehlike kategorisini değerlendirme verisine rastlanmamıştır.

$\mathrm{Bu}$ çalışma ile bu iki türün karşılaştırmalı anatomik, palinolojik ve aken mikromorfolojik özellikleri ilk kez ayrıntılı olarak belirlenerek, türlerin taksonomisine katkı sağlanmıştır.

\section{Materyal ve Metot}

\subsection{Materyalin eldesi}

Araştırmamıza konu teşkil eden taksonların lokalite ve toplayıc bilgileri şu şekildedir:

C. lycopifolia: C6 Hatay: Dörtyol, $100 \mathrm{~m}$. 18.06.2014, H.Dural-3600

C. cheirolopha: C6 Hatay: Dörtyol, $400 \mathrm{~m}$. 18.06.2014, H. Dural-3601

Toplanan örnekler Türkiye Floras1 kullanılarak teşhis edilmiştir. Örnekler yaygin herbaryum tekniklerine göre kurutulmuştur. $\mathrm{Bu}$ örneklerden bir kısmı ise arazi koşullarında \%70'lik etil alkol dolu plastik kaplara konulmuştur.

\subsection{Anatomik yöntemler}

İncelenen türlerin vejetatif organları yaklaşık 1-3 cm'lik parçalar halinde hazırlanıp bu örneklere parafin metodu uygulanmıştır (Johansen, 1940). Parafin metodu ile kesit alınamayan dokulardan el ile enine kesitler alınmıştır. Parafin kesitleri safranin-fastgreen ikili boyaması ile boyanırken el ile alınan kesitler floroglisin- $\mathrm{HCl}$ kullanılarak boyanmıştır. Böylelikle elde edilen kesitler, Leica DM 1000 1şı mikroskobu ve buna tak1l Canon EOS 450D kamera ile fotoğraflanmıştır. Vejetatif organlara ait hücre gruplarının ölçümleri ise Kameram programı kullanılarak yapılmış olup her hücre grubu için en az 40 ölçüm alınmıştır. 
Ölçümlerin; minimum, maksimum, ortalama ve standart sapma değerleri hesaplanarak verilmiştir.

\subsection{Palinolojik yöntemler}

Polen taneleri hem Wodehouse (1935) hem de Erdtman (1960) yöntemleri kullanılarak daimi preparat haline getirilmiştir (Wodehouse, 1935; Erdtman, 1960). Polenler Leica DM 1000 marka mikroskoba takılı Canon EOS 450D marka kamera ile fotoğraflanmış ve Kameram 21 programı yardımıyla ölçümleri gerçekleştirilmiştir. Ölçümler minimum, maksimum, ortalama ve standart sapma şeklinde verilmiştir. Polen terminolojisinde; Wagenitz (1955), Stix (1960), Pınar ve İnceoğlu (1996), Punt vd. (2007), Punt ve Hoen (2009) çalışmalarından yararlanılmıştır. Taramalı elektron mikroskobu ile yapılan çalışmalarda örnekler doğrudan alüminyum stablar üzerine yerleştirilmiştir. Cressington 108 marka altın püskürtücüyle stablar altın tozu ile kaplanmıştır. Böylece hazırlanan staplar Zeiss Evo LS10 model SEM ile incelenmiş ve fotoğraflanmıştır.

\subsection{Aken Mikromorfolojik Yöntemleri}

Aken yüzey özelliklerinin belirlenmesine yönelik çalışmalarda, kağıt torbalarda hava almaları engellenmeyecek şekilde saklanan olgun akenler kullanılmıştır. Her bir takson için en az 30 aken tanesine ait, aken boyu ve eni, pappus boyu mekanik kumpas yardımıyla; karpopodyumdaki foramenin derinliği ve genişliği gibi karakterler Image Tool 1.7 programiyla; aken rengi, stilopodyum rengi, pappus rengi gibi karakterler Işık mikroskobu yardımı ile belirlenmiştir. Ölçülen değerler minimum, maksimum, ortalama ve standart sapma şeklinde verilmiştir. Taramalı elektron mikroskobu çalışmalarında ise, akenler doğrudan stablar üzerine aktarılmıştır. Altın püskürtücü yardımı ile kaplanan örnekler farklı büyütmeler ile fotoğraflanmıştır. Aken terminolojisinde; Dittrich (1968), Haque ve Godward (1984), Bean (2001), Mukherjee ve Nordenstam (2004), Abid ve Qaiser (2009) ve Behjou vd. (2016) çalışmalarından faydalanılmıştır.

\section{Bulgular}

\subsection{Anatomik Bulgular}

\section{Kök anatomisi}

C. cheirolopha ve C. lycopifolia taksonlarının her ikisinin köklerinden alınan enine kesitlerde diştan içe doğru peridermis, korteks ve iletim dokusu olmak üzere üç bölge ayırt edilmektedir. Peridermis, parçalanmış, izodiyametrik şekilli hücrelerden oluşmakta olup kökleri çevrelemektedir. Peridermisin genişliği $C$. cheirolopha'da 8.78-34.88 $\mu \mathrm{m}$ iken $C$. lycopifolia' da 20.49-48.01 $\mu \mathrm{m}$ 'dir (Tablo 1). Korteks tabakası parankimatik karakterli hücrelerden oluşmakta olup peridermisi merkeze doğru izlemektedir. Floem ve ksilem dokuları arasında kambiyum tabakası net bir şekilde ayırt edilememiştir. Kök enine kesitlerinin merkez kısmı ksilem elemanları ile doludur (Şekil 1-a, b).

\section{Gövde anatomisi}

İncelenen türlerin gövde enine kesitlerinin epidermis, korteks parankiması, iletim demetleri ve öz bölgesi olmak üzere dört temel kısımdan oluştuğu belirlenmiştir (Şekil 2-a,c). Epidermis hücreleri dikdörtgenimsiyuvarlak şekilli olup ince bir kutikula tabakası ile örtülmüştür. Korteks parankimatik hücreleri yer yer uzun silindirik şekilli olup bol miktarda kloroplast ihtiva etmektedirler. Bazı korteks hücreleri ise yuvarlak şekilli olup daha az kloroplast 
içermektedir. Gövdelerin bazı kısımlarında çıkıntılar mevcut olup bu çıkıntılarda kollenkima hücreleri yer almaktadır (Şekil 2b,c). Korteks tabakasını tek siralı endodermis tabakası izlemektedir. İletim demetleri gövdede kesintisiz bulunmaktadır. Floem çevreye doğru iken ksilem merkeze doğru konumlanmaktadır. Floem hücrelerinin hemen üzerinde yarım ay şeklinde sklerenkimatik hücreler yer almaktadır. Gövdelerin merkezinde parankimatik karakterli olan öz hücreleri yer almakta olup, bu hücrelerin boyutları C. cheirolopha'da $16.72-84.84 \mu \mathrm{m}$ ve $C$. lycopifolia'da ise 12.24-80.03 $\mu \mathrm{m}$ arasında değişmektedir (Şekil 2-a,c; Tablo 1).

\section{Yaprak anatomisi}

Yaprak enine kesitlerinde epidermis hücrelerinin her iki yüzeyde bulunduğu gözlemlenmiştir (Şekil 3-a,c). Üst epidermis hücreleri C. cheirolopha'da dikdörtgen şekilli ve hücre boyutları 17.03-46.55×6.34$50.23 \mu \mathrm{m}$, alt epidermis hücreleri ise ovaldikdörtgenimsi şekilli olup boyutları 4.6217.76×4.38-24.02 $\mu \mathrm{m}$ 'dir (Tablo 1). $C$. lycopifolia'da üst epidermis hücreleri ovaldikdörtgenimsi şekili, boyutları 8.63$26.93 \times 7.89-42.57 \mu \mathrm{m}$, alt epidermis hücreleri ise oval-dikdörtgenimsi şekilli olup boyutları 12.59-81.48×15.14-65.32 $\mu \mathrm{m}$ 'dir (Tablo 1). C. cheirolopha türü üst epidermis hücreleri alt epidermis hücrelerinden oldukça büyüktür (Şekil 3-b). Buna karşın C. lycopifolia'da üst epidermis hücreleri ve alt epidermis hücreleri boyut olarak birbirine benzer (Şekil 3-d). Mezofil dokusu ekvifasiyal tiptedir. Yaprak orta damarında C. cheirolopha'da üç iletim demeti bulunmakta olup bunlardan birisi diğer ikisine oranla oldukça büyüktür (Şekil 3-a). C. lycopifolia'da ise yaprak orta damarında tek büyük bir iletim demeti bulunmaktadır (Şekil 3-d).
Araştırılan taksonların diğer anatomik hücrelerine ait sayısal değerler Tablo 1'de verilmiștir.

\subsection{Palinolojik Bulgular}

\section{Centaurea lycopifolia}

Polenler monad, izopolar ve trikolporat. Ekvatoral eksen 35.66-38.95 $\mu \mathrm{m}$, ekvatoral görünüş eliptik ve kutuplarda basık, polar eksen 34.72-38.55 $\mu \mathrm{m}$, polar görünüş yuvarlak, P/E oranı 1.00, prolat-sferoidal, amb 9,32 $\mu \mathrm{m}$, triangular-sferoidal, kolpus 27,8 $\mu \mathrm{m}$ uzunluğunda, 7,83 $\mu \mathrm{m}$ genişliğinde, ektoapertür lolongat kolpus, oldukça uzun, hafifçe içeriye çökük, ornamentasyonu granüllü, kolpus uçları akut, mezoapertür lalongat kolpus, endoapertür lalongat kolpus, çok uzun, bir endocinguluma dönüşmüş, por 11,31 $\mu \mathrm{m} \quad$ uzunluğunda, 11,61 $\mu \mathrm{m}$ genişliğinde, yuvarlak, apokolpiyum 24,51 $\mu \mathrm{m}$, ektekzin $1,51 \mu \mathrm{m}$, endekzin $1,11 \mu \mathrm{m}$, intin $0,98 \mu \mathrm{m}$, kosta 2.20-3.85 $\mu \mathrm{m}$ kalınlığında, ekzin skülptürü skabratperforat, $10 \mu \mathrm{m}^{2}$, deki spin say1s1 9-13, spinler $0,88 \mu \mathrm{m}$ uzunluğunda, spinlerin tabanı 2,45 $\mu \mathrm{m}$ genişliğinde, spinler arası uzaklık $0,89 \mu \mathrm{m}, \quad$ spin tabanındaki perforasyon tek sıralı ve aynı büyüklükte (Şekil 4-5).

\section{Centaurea cheirolopha}

Polenler monad, izopolar ve trikolporat. Ekvatoral eksen 21.93-27.96 $\mu \mathrm{m}$, ekvatoral görünüş eliptik ve kutuplarda basık, polar eksen 24.54-29.15 $\mu \mathrm{m}$, polar görünüş yuvarlak, P/E oran1 1.04, prolat-sferoidal, amb $8,43 \mu \mathrm{m}$ çapında, triangular-sferoidal, kolpus 20,48 $\mu \mathrm{m}$ uzunluğunda 4,69 $\mu \mathrm{m}$ genişliğinde, ektoapertür lolongat kolpus, oldukça uzun, hafifçe içeriye çökük, ornamentasyonu granüllü, kolpus uçları akut, mezoapertür lalongat kolpus, endoapertür lalongat kolpus, çok uzun, bir endocinguluma 
dönüşmüş, por $7,22 \mu \mathrm{m}$ uzunluğunda 7,78 $\mu \mathrm{m}$ genişliğinde, yuvarlak, apokolpiyum $17,02 \mu \mathrm{m}$, ektekzin $1,26 \mu \mathrm{m}$, endekzin 1,19 $\mu \mathrm{m}$, intin $0,74 \mu \mathrm{m}$, kosta $1.76-3.52 \mu \mathrm{m}$ kalınlığında, ekzin skülptürü skabratperforat, $10 \mu \mathrm{m}^{2}$ deki spin sayıs $8-11$, spinler $0,77 \mu \mathrm{m}$ uzunluğunda, spinlerin tabanı $3,37 \mu \mathrm{m}$ genişliğinde, spinler arası uzaklık $0,82 \mu \mathrm{m}, \quad$ spin tabanındaki perforasyon tek sıralı ve aynı büyüklükte (Şekil 6-7).

Tablo 1. İncelenen taksonların anatomik hücrelerine ait sayısal değerler $(\mu \mathrm{m})$

\begin{tabular}{|c|c|c|c|c|c|c|c|c|}
\hline \multirow[t]{2}{*}{ Türler } & \multirow[t]{2}{*}{ Organ } & & \multicolumn{3}{|c|}{ Genişlik } & \multicolumn{3}{|c|}{ Uzunluk } \\
\hline & & & Min & Max & Ort \pm SD & Min & Max & Ort \pm SD \\
\hline \multirow{16}{*}{ 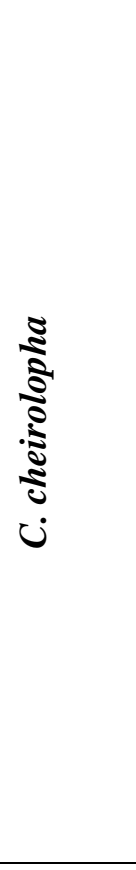 } & Kök & Peridermis & 8.78 & 34.88 & $19.15 \pm 6.21$ & - & - & - \\
\hline & & $\begin{array}{l}\text { Korteks } \\
\text { parankiması }\end{array}$ & 14.47 & 63.65 & $39.72 \pm 11.07$ & 16.8 & 41.56 & $27.02 \pm 5.67$ \\
\hline & & Trake & 5.59 & 30.31 & $18.24 \pm 5.53$ & - & - & - \\
\hline & Gövde & Kutikula & 2.5 & 6.99 & $4.18 \pm 1.07$ & & & \\
\hline & & Epidermis & 4.73 & 17.42 & $10.26 \pm 2.76$ & 6.25 & 16.33 & $11.24 \pm 2.33$ \\
\hline & & Kollenkima & 4.45 & 17.11 & $10.67 \pm 3.04$ & - & - & - \\
\hline & & Sklerenkima & 7.76 & 16.91 & $10.11 \pm 3.43$ & & & \\
\hline & & Trake & 10.78 & 27.52 & $18.20 \pm 4.4$ & - & - & - \\
\hline & & Öz & 16.72 & 84.84 & $38.14 \pm 14.38$ & - & - & - \\
\hline & Yaprak & Üst Kutikula & 3.64 & 12.03 & $7.61 \pm 1.91$ & - & - & - \\
\hline & & Alt Kutikula & 0.73 & 3.54 & $1.91 \pm 0.56$ & - & - & - \\
\hline & & $\begin{array}{l}\text { Palizat } \\
\text { parankiması }\end{array}$ & 30.39 & 63 & $44.55 \pm 7.15$ & 6.95 & 19.04 & $12.25 \pm 3.18$ \\
\hline & & $\begin{array}{l}\text { Sünger } \\
\text { parankiması }\end{array}$ & 7.21 & 17.37 & $11.69 \pm 2.28$ & - & - & - \\
\hline & & Mezofil & 115.77 & 163.95 & $143.15 \pm 9.16$ & - & - & - \\
\hline & & Üst epidermis & 6.34 & 50.23 & $28.44 \pm 11.55$ & 17.03 & 46.55 & $28.75 \pm 6.05$ \\
\hline & & Alt epidermis & 4.38 & 24.02 & $19.92 \pm 4.58$ & 4.62 & 17.76 & $9.18 \pm 2.71$ \\
\hline \multirow{16}{*}{ 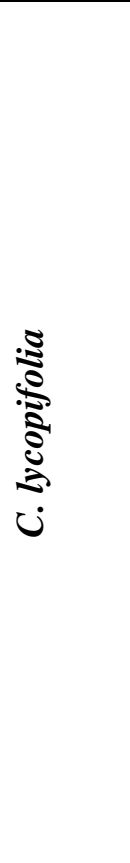 } & Kök & Peridermis & 20.49 & 48.01 & $35.54 \pm 6.32$ & & & \\
\hline & & $\begin{array}{l}\text { Korteks } \\
\text { parankiması }\end{array}$ & 10.43 & 45.35 & $21.25 \pm 8.51$ & 7.71 & 23.93 & $13.81 \pm 2.96$ \\
\hline & & Trake & 9.11 & 23.92 & $16.26 \pm 4.16$ & - & - & - \\
\hline & Gövde & Kutikula & 2.47 & 8.4 & $4.84 \pm 1.13$ & - & - & - \\
\hline & & Epidermis & 5.15 & 26.48 & $12.71 \pm 15.13$ & 10.38 & 26.18 & $16.88 \pm 3.02$ \\
\hline & & Kollenkima & 6.41 & 32.43 & $19.57 \pm 5.44$ & - & - & - \\
\hline & & Sklerenkima & 6.25 & 18.02 & $11.83 \pm 2.66$ & - & - & - \\
\hline & & Trake & 6.17 & 28.3 & $16.24 \pm 4.8$ & - & - & - \\
\hline & & Öz & 12.24 & 80.03 & $39.75 \pm 14.9$ & - & - & - \\
\hline & Yaprak & Üst Kutikula & 1.34 & 3.66 & $2.44 \pm 0.49$ & - & - & - \\
\hline & & Alt Kutikula & 1.31 & 3.76 & $2.44 \pm 0.54$ & - & - & - \\
\hline & & $\begin{array}{l}\text { Palizat } \\
\text { parankiması }\end{array}$ & 12.66 & 34.11 & $21.12 \pm 4.43$ & 39.48 & 86.38 & $56.4 \pm 8.93$ \\
\hline & & $\begin{array}{l}\text { Sünger } \\
\text { parankiması }\end{array}$ & 11.99 & 37.75 & $23.43 \pm 5.56$ & - & - & - \\
\hline & & Mezofil & 208.3 & 308.23 & $257.68 \pm 23.33$ & - & - & - \\
\hline & & Üst epidermis & 7.89 & 42.57 & $22.7 \pm 9.44$ & 8.63 & 26.93 & $15.91 \pm 4.97$ \\
\hline & & Alt epidermis & 15.14 & 65.32 & $31.36 \pm 10.5$ & 12.59 & 81.48 & $27 \pm 14.27$ \\
\hline
\end{tabular}




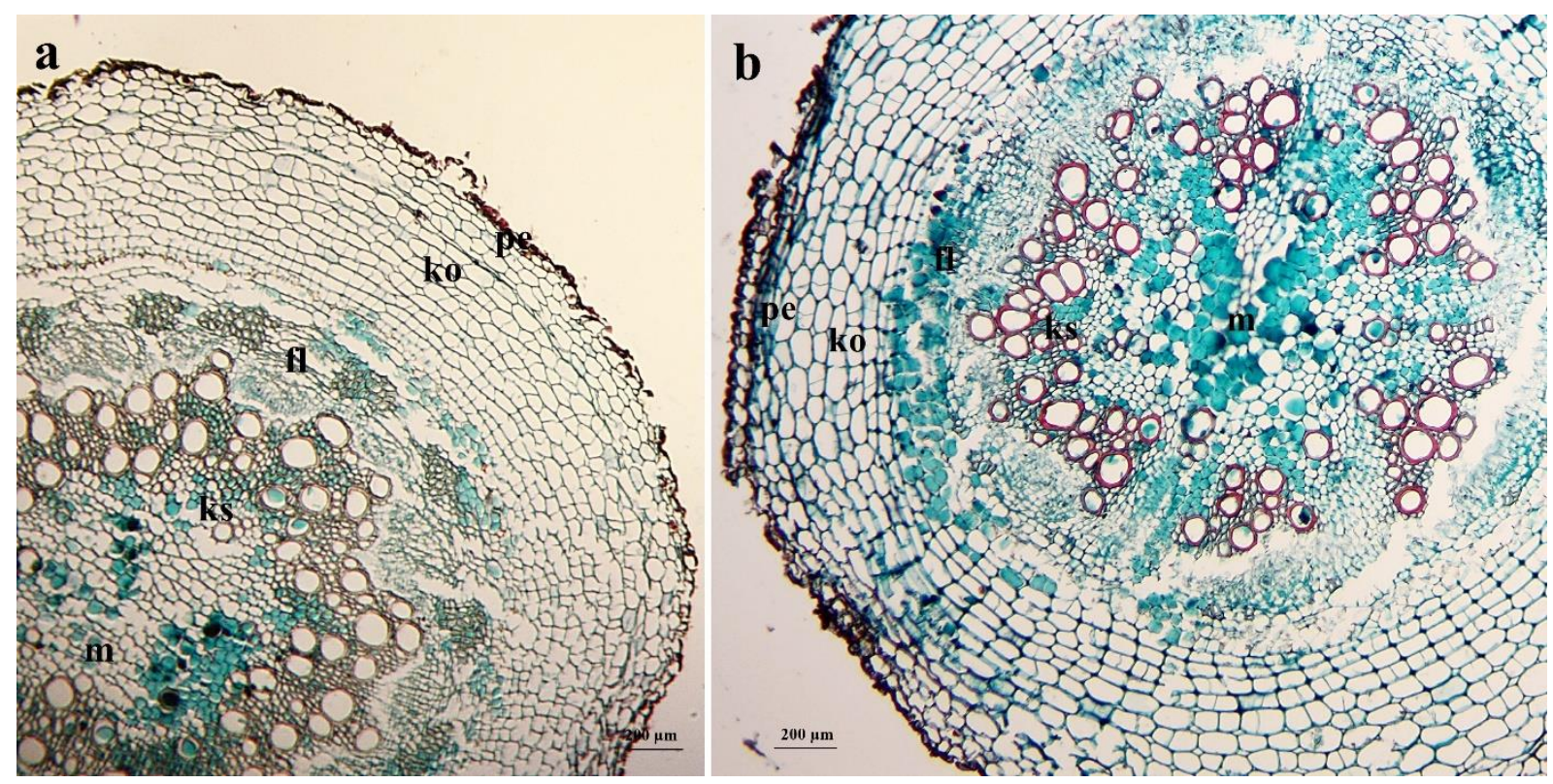

Şekil 1. C. cheirolopha ve C. lycopifolia taksonlarının kök enine kesitleri a. C. cheirolopha b. C. lycopifolia pe: peridermis, ko: korteks parankiması, fl: floem, ks: ksilem, m: merkez bölge
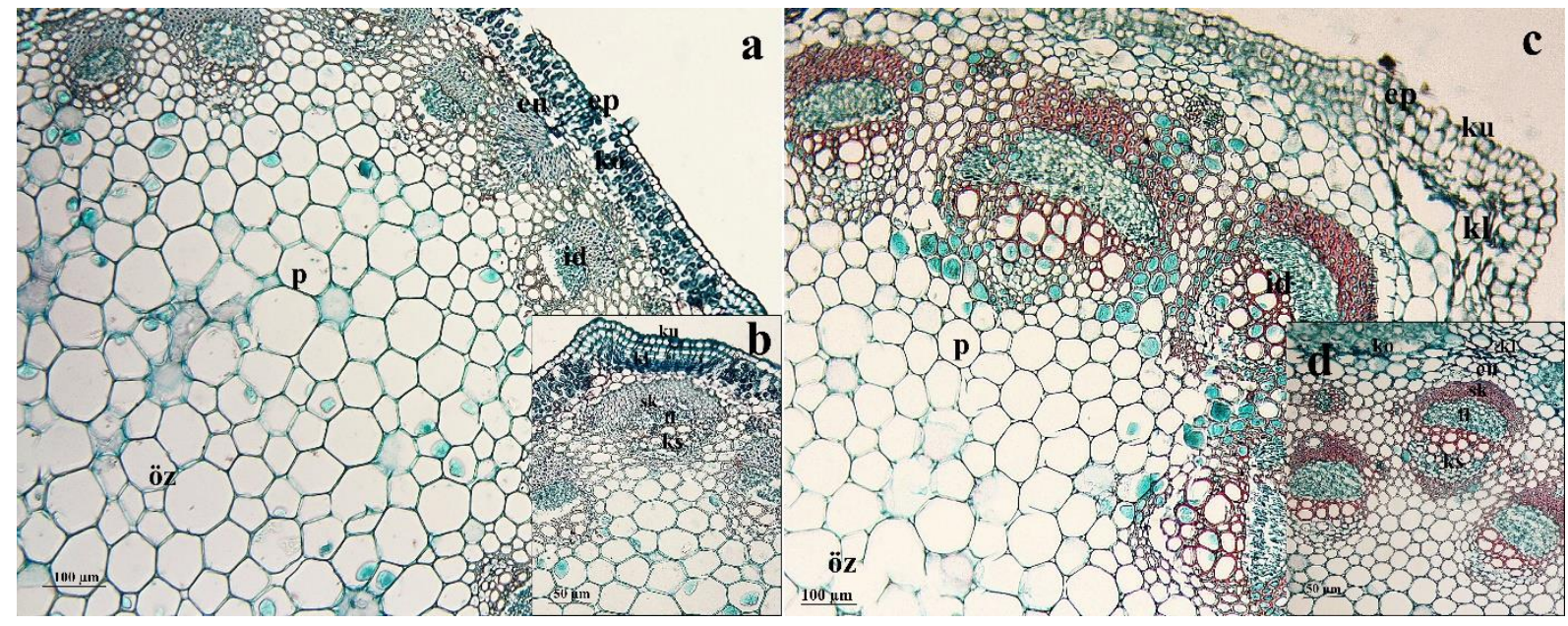

Şekil 2. $C$. cheirolopha ve $C$. lycopifolia taksonlarının gövde enine kesitleri a-b. $C$. cheirolopha c-d. C. lycopifolia ku: kutikula, ep: epidermis, ko: korteks parankiması, en: endodermis, id: iletim demeti, kl: kollenkima, sk: sklerenkima, fl: floem, ks: ksilem, p: parankima hücresi 


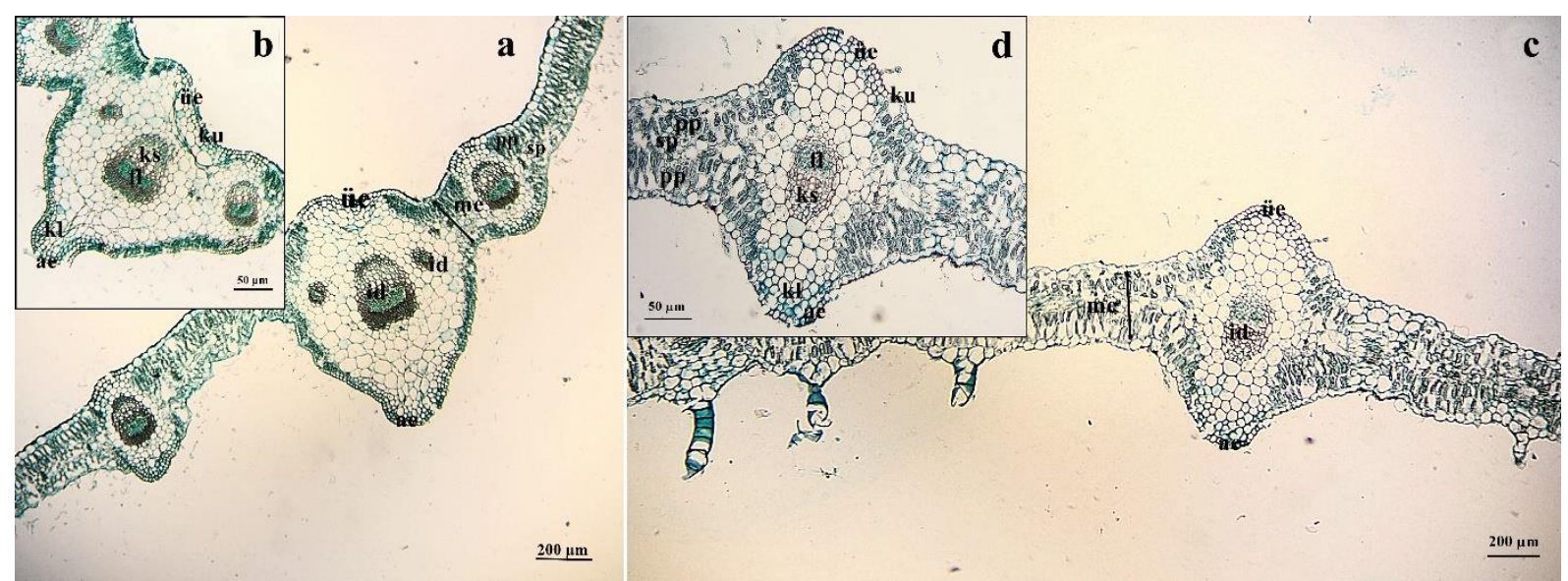

Şekil 3. C. cheirolopha ve $C$. lycopifolia taksonlarının yaprak enine kesitleri a-b. $C$. cheirolopha c-d. C. lycopifolia ku: kutikula, üe: üst epidermis, ae: alt epidermis, kl: kollenkima, id: iletim demeti, me: mezofil, fl: floem, ks: ksilem, pp: palizat parankiması, sp:

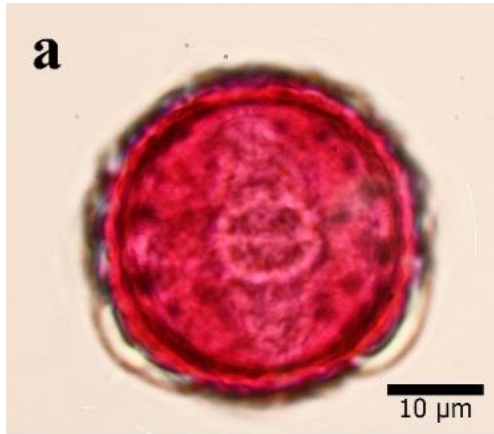
sünger parankiması
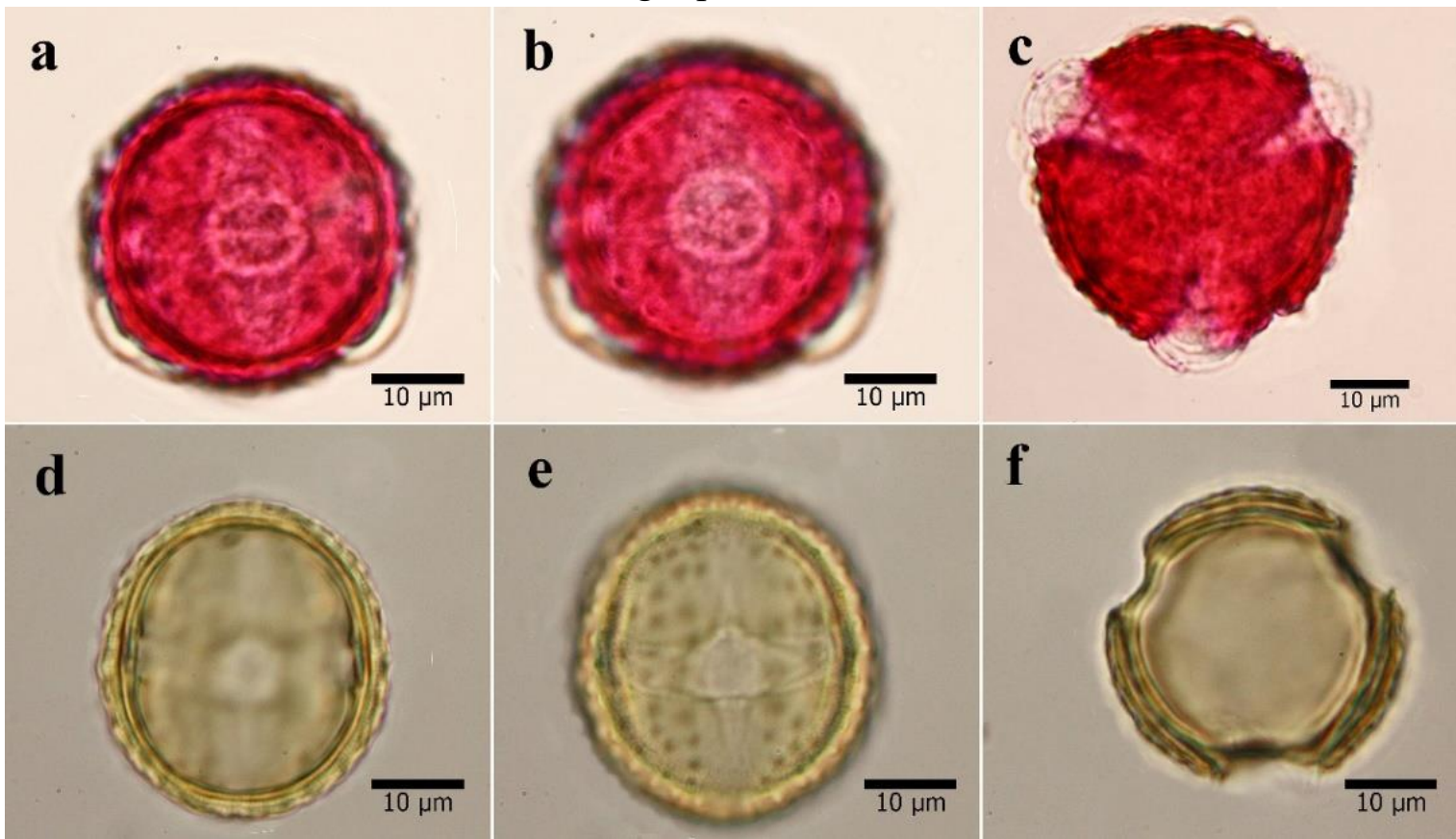

Şekil 4. C. lycopifolia taksonuna ait polenin 1şık mikroskobu görüntüleri a-c. Wodehouse d-f. Asetoliz 

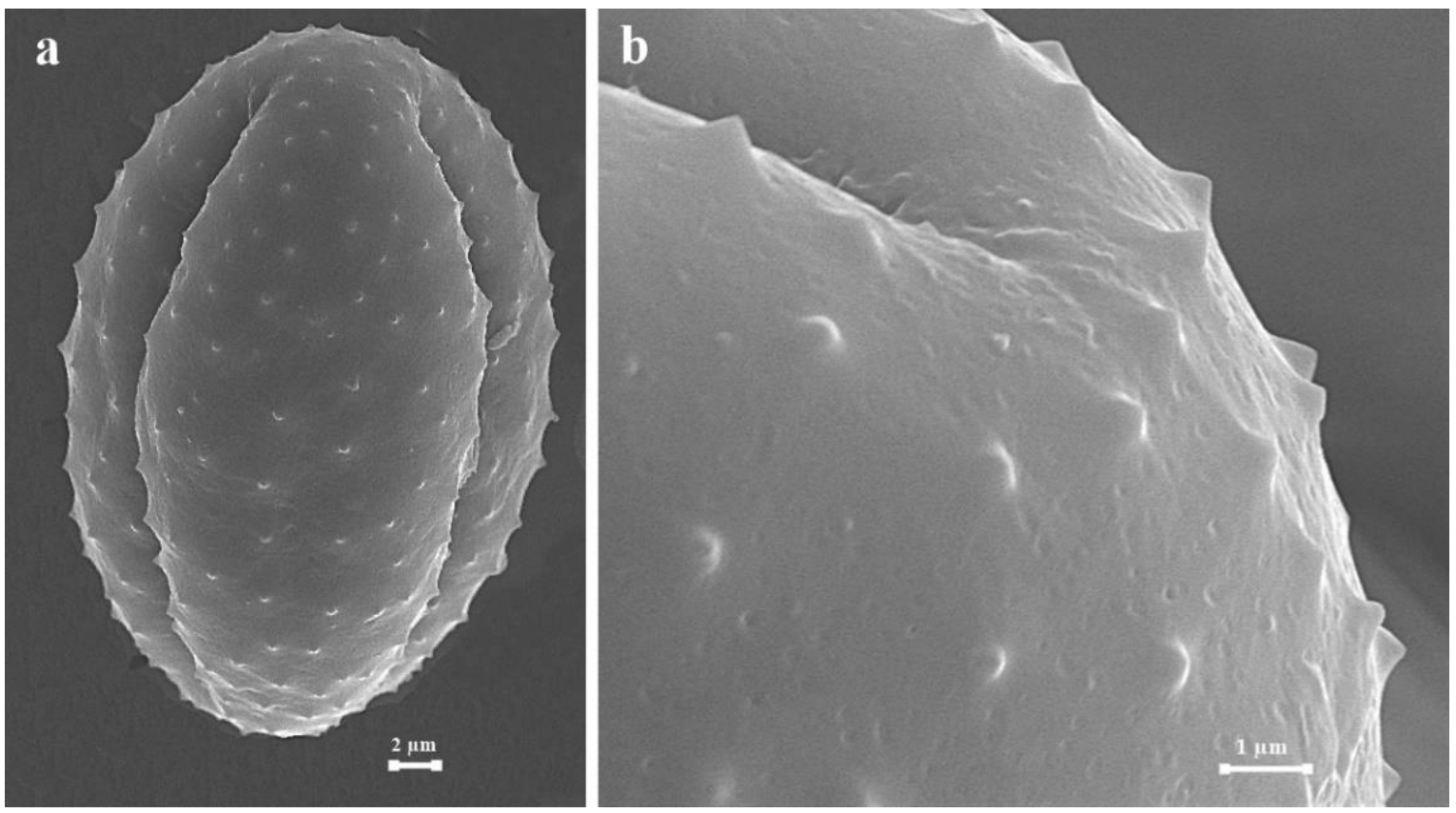

Şekil 5. C. lycopifolia taksonuna ait polenin SEM görüntüleri a. Ekvatoral görünüş b. Ornamentasyon

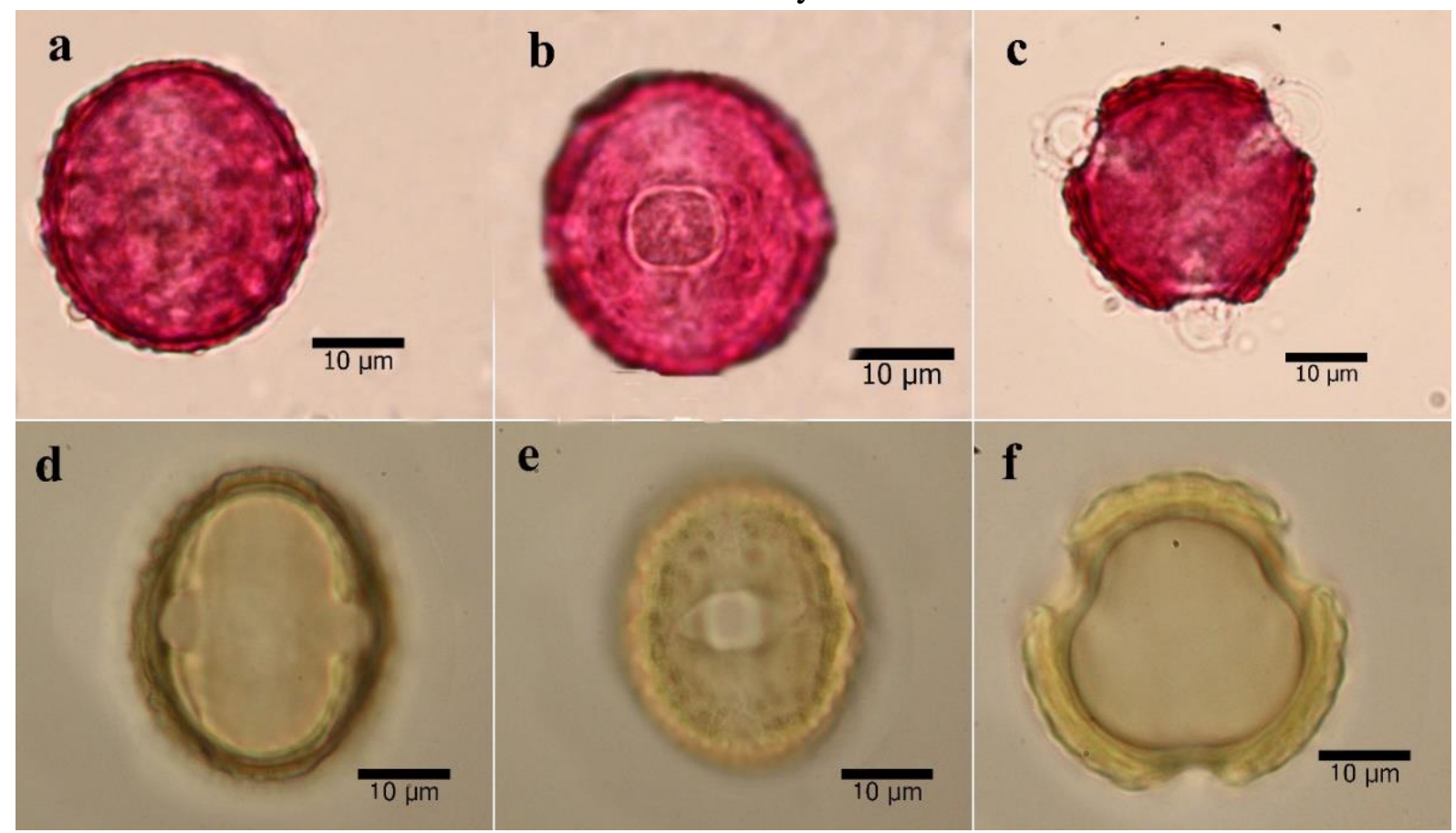

Şekil 6. C. cheirolopha taksonuna ait polenin 1ş1k mikroskobu görüntüleri a-c. Wodehouse df. Asetoliz 


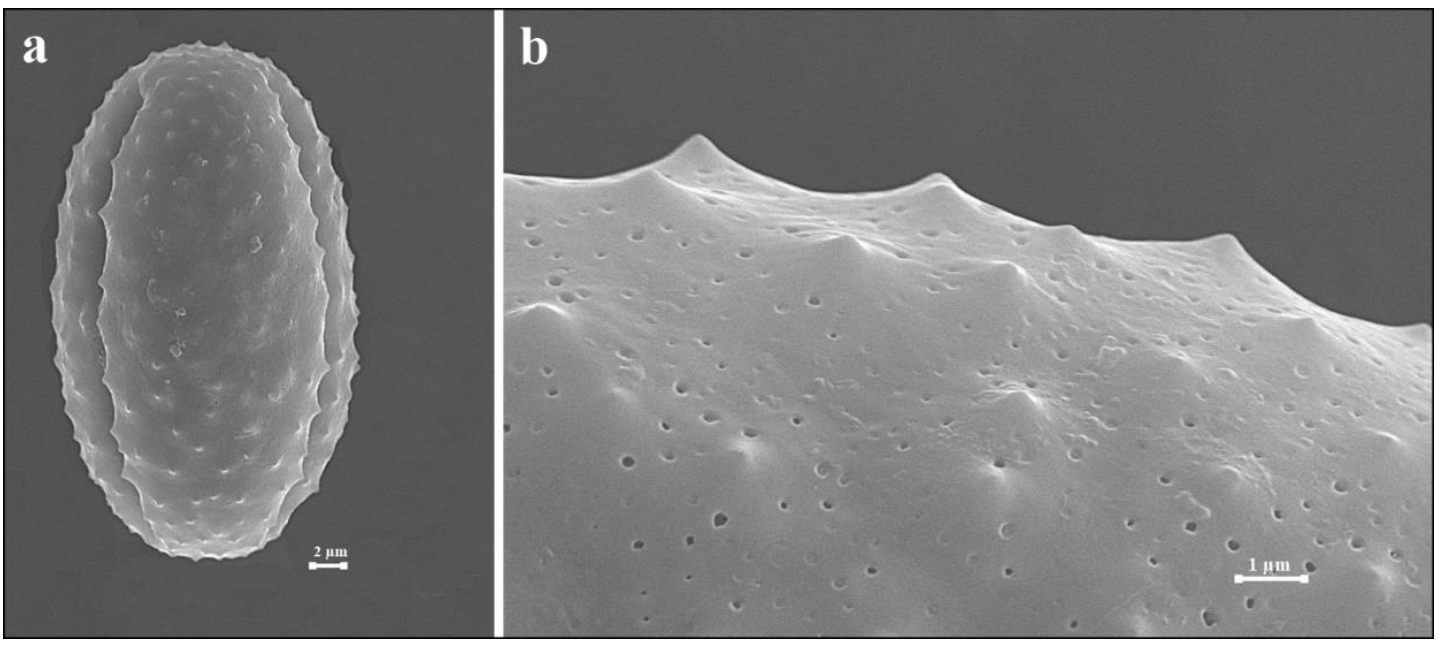

Şekil 7. Centaurea cheirolopha taksonuna ait polenin SEM görüntüleri a. Ekvatoral görünüş

\section{b. Ornamentasyon}
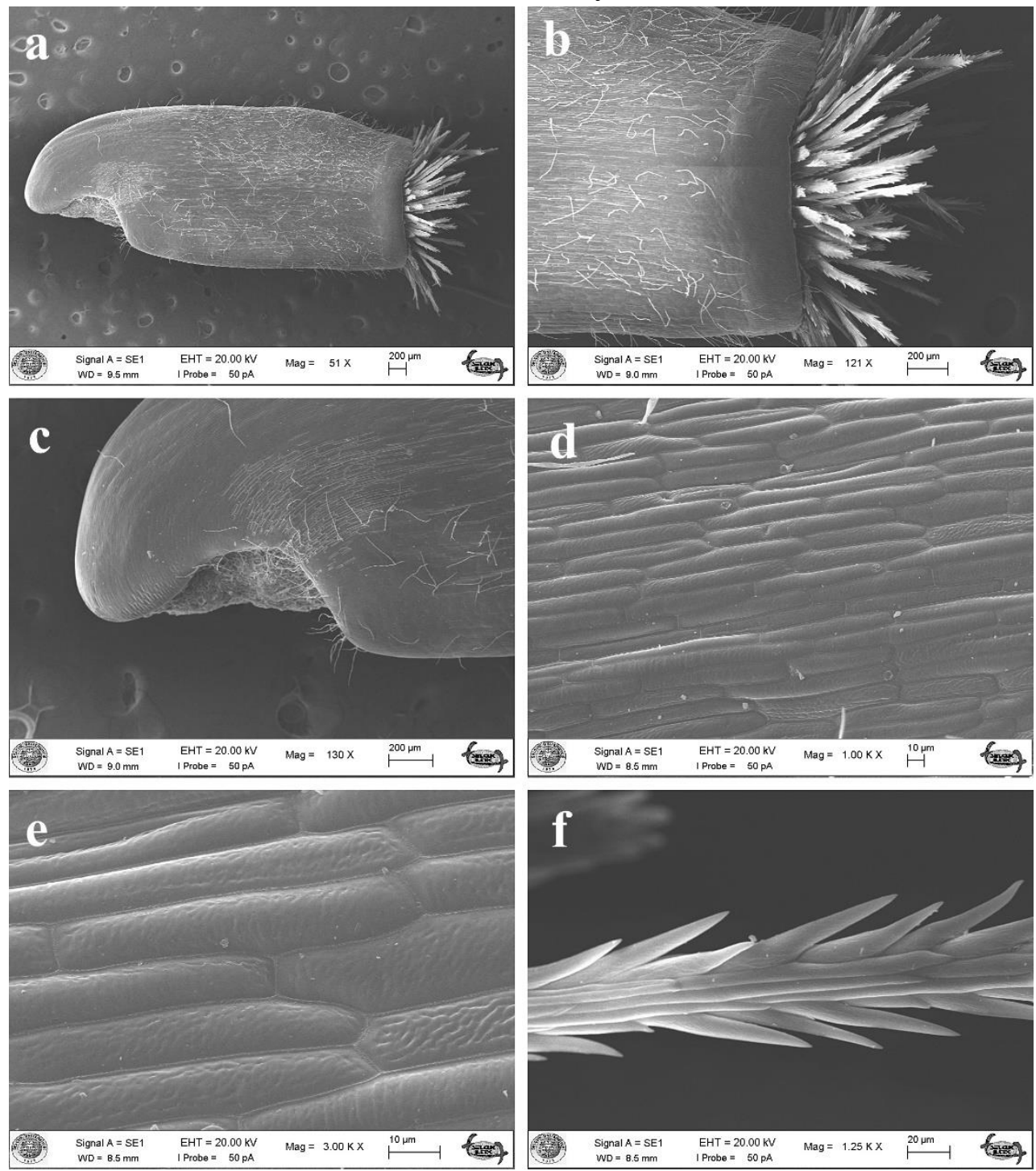

Şekil 8. C. lycopifolia taksonuna ait akenin SEM görüntüleri a. Genel görünüş, b.

Stilopodyum yakın görünüş, c. Karpopodyum yakın görünüş, d. Ornamentasyon, e. Ornamentasyon yakın görünüş, f. Pappus yakın görünüş 

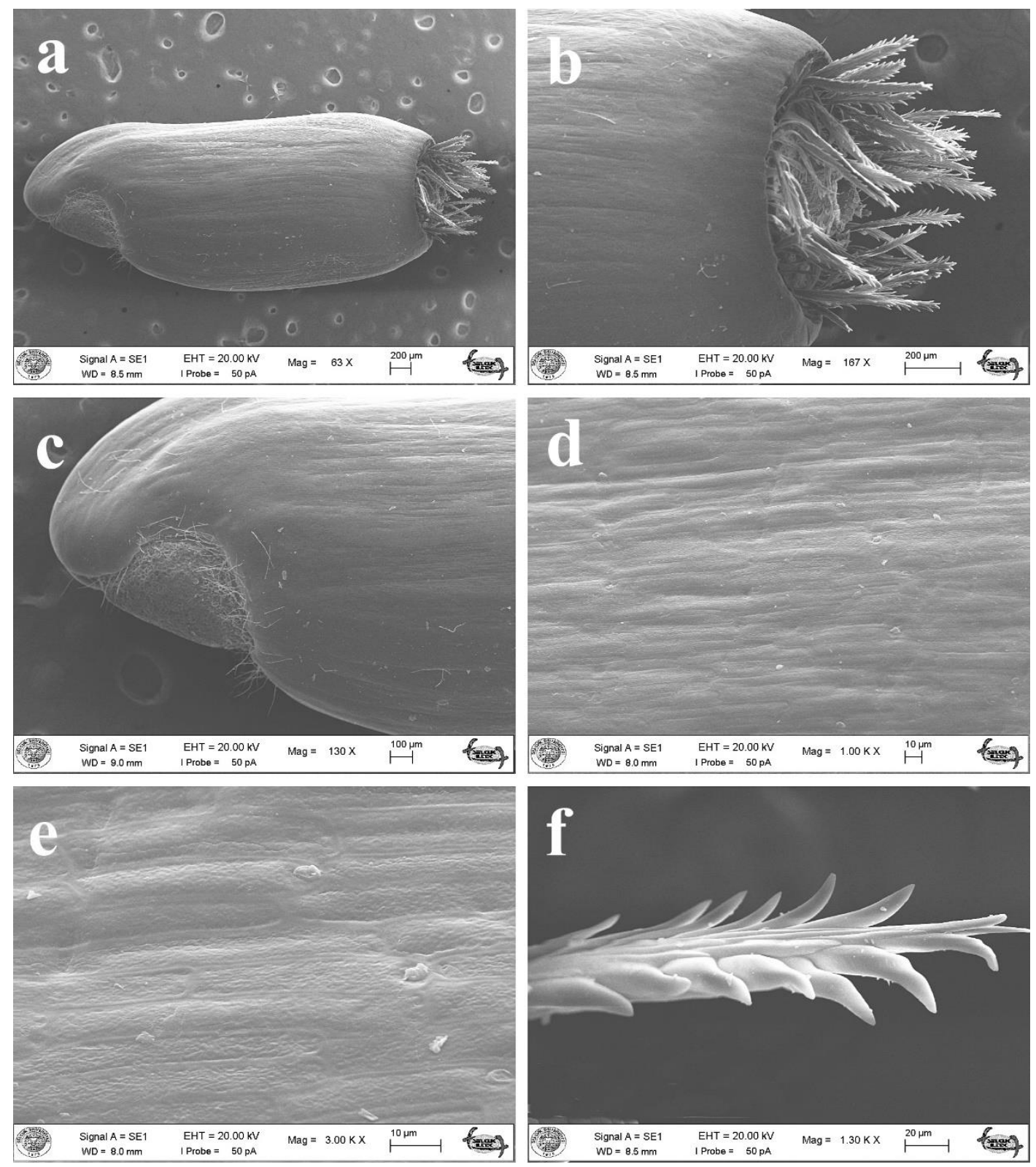

Şekil 9. C. cheirolopha taksonuna ait akenin SEM görüntüleri a. Genel görünüş, b. Stilopodyum yakın görünüş, c. Karpopodyum yakın görünüş, d. Ornamentasyon, e. Ornamentasyon yakın görünüş, f. Pappus yakın görünüş.

\subsection{Aken Mikromorfolojik Bulguları}

\section{Centaurea lycopifolia}

Aken 3.21-4.77×1.70-2.34 mm, oblanseolat, açık kahverengi-saman renkli, stilopodyum dalgalı ve tüysüz, korona mevcut ve krem renkli, karpopodyum girintili ve tüylü,
$363.45 \mu \mathrm{m}$ derinlikte, $984.88 \mu \mathrm{m}$ genişlikte. Aken yüzeyi sitriyat, sık tüylü, epidermis hücreleri dikdörtgen şekilli, ucu akut ya da düz, 58.01-103.97×10.34-13.78 $\mu \mathrm{m}$. Pappus basit, $\quad 7.97-12.18 \mathrm{~mm}$ uzunluğunda, dökülücü, genç iken açık kahverengi renkli, olgunlaştığı zamansa koyu kahverengi renkli, pappus kılları halka şeklinde dizilmiş, kılçık 
sık dizilimli, kılçık tabanı düz, iğne şeklinde, skabroz (Şekil 8).

\section{Centaurea cheirolopha}

Aken 3.98-5.05×1.81-2.31 mm, oblanseolat, kahverengi-saman renkli, krem rengi çizgili, stilopodyum dalgalı ve tüysüz, korona mevcut ve krem renkli, karpopodyum girintili ve tüylü, $273.18 \mu \mathrm{m}$ derinlikte, $767.50 \mu \mathrm{m}$ genişlikte. Aken yüzeyi sitriyat, çok seyrek tüylü, epidermis hücreleri dikdörtgen şekilli, ucu akut ya da düz, 54.2581.56×8.29-11.42 $\mu \mathrm{m}$. Pappus basit, 9.31$11.40 \mathrm{~mm}$ uzunluğunda, dökülücü, açık kahverengi-krem renkli, pappus kılları halka şeklinde dizilmiş, kılçıklar sık dizilimli, iğne şeklinde, skabroz, kılçık tabanı şişkinleşmiş (Şekil 9).

\section{Sonuç ve Tartışma}

Centaurea cinsinin kök anatomik yapısında sekonder kök yapısı gözlemlenmiştir (Kaya vd. 2010). C. cheirolopha ve C. lycopifolia taksonları da benzer kök anatomik yapısına sahiptir.

C. cheirolopha ve C. lycopifolia türlerinin gövdelerinde 8-9 siralı kollenkima hücreleri yer almaktadır. $C$. sessilis Willd. ve $C$. armena Boiss. taksonlarında 1 siralı kollenkima dokusundan bahsedilmiştir (Aydın vd., 2013). Ek olarak, C. kilaea Boiss., C. helenoides Boiss. \& Hausskn. ex Boiss., $C$. huber-morathii Wagenitz, $C$. hedgei Wagenitz ve $C$. appendicigera $\mathrm{K}$. Koch taksonlarında, kollenkima dokusu 5-6 sıralı olarak bildirilmiştir (Aydın vd.,, 2013). Yentür (2003), iletim demetlerinin düzenlenişinin karşılaştırmalı anatomik çalışmalarda önemli bilgiler sağladığını bildirmiştir. C. lycopifolia' da 2 halkada, $C$. cheirolopha'da bir halkada dizilmiş iletim demetleri tespit edilmiştir.

Centaurea cinsinde, yaprak anatomik yapısında, palizat parankimasının sira sayısı, ve sünger parankimasının şeklinin taksonların ayrımında ayırt edici karakterler olarak kullanılabileceği bildirilmiştir (Uysal vd., 2005; Celik vd., 2005, 2008; Kaya vd., 2010; Aydın vd., 2013). C. cheirolopha, üst epidermisin hemen altında 1-2 siralı palizat parankimasina sahipken $C$. lycopifolia ise her iki yüzeyde 1-2 sıralı palizat parankimasına sahiptir. Her iki takson ekvifasiyal tip mezofil dokusuna sahiptir. C. lycopifolia'da yaprak orta damarında büyük bir iletim demeti bulunmakta olup $C$. cheirolopha'da ise yaprak orta damarında üç iletim demeti yer almaktadır.

Centaurea cinsine ait olan polen taneleri, Wagenitz (1955)'e göre, Centaurium, Dealbata, Montana, Cyanus, Scabiosa ya da Jacea; Stix (1960)'a göre Centaurea; Punt ve Hoen (2009)'a göre Centaurea nigra, $C$. scabiosa ya da $C$. cyanus olarak sinıflandırılabilirler. İncelediğimiz taksonların polen taneleri prolat-sferoidal olarak gözlemlenmiş ve Wagenitz'e (1955) göre; $C$. lycopifolia ve $C$. cheirolopha taksonlarının her ikisi de Cyanus tip, Punt ve Hoen'e (2009) göre C. nigra tipe yakın bulunmuştur.

Asteraceae familyasinda spin ya da spinüllerin tabanındaki perforasyonlar, taksonları ayırmada iyi tanımlanmış bir taksonomik karakterdir (Stix, 1960; Pinar ve Dönmez, 2000; Pınar vd., 2016; Skvarla vd., 1977; Salgado-Labouriau, 1982; Mesfin vd., 1995; Erkara vd., 2012). Dahası, Wagenitz (1976)' göre Asteraceae familyası için spinlerdeki küçülme ileri bir karakterdir. Buna paralel olarak bazı araştırmacılar 
Asteraceae familyasında, spinler arasındaki ornamentasyonun önemli bir polen karakteri olduğunu iddia etmişlerdir (Çeter vd., 2013; Mesfin vd., 1995; Kodak vd., 2012). Fakat araştırılan taksonlarda, spinler arası ornamentasyon sadece perforat olduğu için bu konuda farklı bir görüş belirlemek mümkün olmamıştır.

Asteraceae familyası polen özellikleri ile olduğu kadar aken morfolojik ve mikromorfolojik karakterleri ile de birçok araştırıcının ilgisini çekmiştir (Dittrich, 1968; Haque ve Godward, 1984; Ertuğrul vd.,2004; Mukherjee ve Nordenstam, 2004; Uysal, 2006; Abid ve Qaiser, 2009; İnceer vd., 2012; Behjou vd., 2016; Candan vd., 2016; Coşkunçelebi vd., 2016; Karanović vd., 2016). Aken boyutları incelendiği zaman taksonların benzerlik gösterdiği tespit edilmiştir. C. cheirolopha taksonu aken rengi açısından krem renkli çizgiler içermesiyle $C$. lycopifolia taksonundan ayrılmaktadır. Her iki takson da aken yüzeyinde tüy ihtiva etmektedir. Karpopodyum belirgin ve ilk bakışta göze çarpmaktadır.

Birçok araştırıcı pappusu, kaliksin bir tür modifiye hali olarak değerlendirmektedir (Cronquist, 1977; Thome, 1983; Takhtajan, 1997). İncelediğimiz taksonların her ikisinde skabroz ve dökülücü pappus bulunmaktadır. Pappusu dökülücü olan taksonların yayılış gösterdikleri alanların kurak olduğu söylenebilir.

$\mathrm{Bu}$ araştırma neticesinde Türkiye için endemik olan iki Centaurea taksonu $C$. lycopifolia ve $C$. cheirolopha anatomik açıdan ilk kez karşılaştırılmıştır. Anatomik karakterler bakımından gövde ve yaprak anatomisinde farklilıklar olduğu tespit edilmiştir. Gövdede, korteks tabakası ve sıra sayısı, sklerenkimanın varlığı ya da yokluğu, iletim demetlerinin sayıs1; yapraklarda, mezofil tipi ve yaprak orta damarındaki iletim demet sayısının, polen ornamentasyon karakterlerinin, aken yüzeyindeki epidermal hücrelerin özelliklerinin taksonları ayırt etmede kullanılabilecek karakterler olduğu belirlenmiştir. $\mathrm{Bu}$ çalışma, gelecekte yapılacak diğer anatomik, palinolojik ya da aken mikromorfolojik araştırmalara yol gösterir nitelikte olacaktır.

Teşekkür: $\mathrm{Bu}$ çalışma Selçuk Üniversitesi Fen Bilimleri Enstitüsü'nde yürütülen Yüksek Lisans Tez çalışmasından elde edilmiştir. Bu çalışmayı 17201018 no’lu proje ile destekleyen Selçuk Üniversitesi Bilimsel Araştırmalar Koordinatörlüğüne teşekkür ederiz.

\section{Kaynaklar}

Abid, R., Qaiser, M. (2009). "Taxonomic significance of the cypsela morphology in the tribe Anthemideae (Asteraceae) from Pakistan and Kashmir", Pakistan Journal of Botany, 41, 555-579.

Anderberg, A.A., Elden, P. (2007). "Tribe Inuleae Cass.", The families and genera of flowering plants, Springer, Berlin, 374-391.

Armağan, M., Uysal, T. (2018). “Centaurea kirmacii (Asteraceae), a new species from Southwestern Anatolia, Turkey", Phytotaxa, 362, 233-238.

Aydın, Ö., Coşkunçelebi, K., Gültepe, M., Güzel, M.E. (2013). "A contribution to taxonomy of Centaurea including Psephellus (Asteraceae) based on anatomical and molecular data", Turkish Journal of Botany, 37, 419-427.

Bean, A. (2001). "Pappus morphology and terminology in Australian and New Zealand thistles (Asteraceae, tribe Cardueae)", Austrobaileya, 6, 139-152.

Behçet, L., İlçim, A., Yapar, Y. (2017). "Centaurea bingoelensis (Asteraceae), a new 
species from Turkey", Turkish Journal of Botany, 41, 180-188.

Behjou, A. M., Sonboli, A., Riahi, H., Osaloo, S.K. (2016). "Achene micromorphology in Tanacetum (AsteraceaeAnthemideae) and its taxonomic and phylogenetic implications", FloraMorphology, Distribution, Functional Ecology of Plants, 222, 37-51.

Bona, M. (2015). "Centaurea goksivriensis (Asteraceae), a new species from Turkey", Phytotaxa, 203, 63-68.

Candan, F., Uysal, T., Tugay, O., Bozkurt, M., Ertuğrul, K., Demirelma, H. (2016). "The examinations of achene ultrastructural features of section Acrolophus (Centaurea, Asteraceae) via scanning electron microscopy", Turkish Journal of Botany, 40, 147-163.

Coşkunçelebi, K., Makbul, S., Okur, S. (2016). "Studies on the achene morphology of Turkish species of Scorzonera L. (Asteraceae) using light and scanning electron microscopy", Phytotaxa, 247, 1-26.

Cronquist, A. (1977). "The compositae revisited", Brittonia, 29, 137-153.

Çelik, S., Uysal, I., Menemen, Y. (2005). "Centaurea species in Turkey (A): Centaurea odyssei Wagenitz (Asteraceae) in Kazdagi (Mt. Ida) National Park", International Journal of Biodiversity Science and Management, 1, 113-120.

Çeter, T., Pınar, N. M., İnceer, H., Hayırlıoglu-Ayaz, S., Yaprak, A. E. (2013). "The comparative pollen morphology of genera Matricaria L. and Tripleurospemum Sch. Bip. (Asteraceae) in Turkey", Plant Systematics and Evolution, 299, 959-977.

Dittrich, M. (1968). "Karpologische Untersuchungen zur Systematik von Centaurea und verwandten Gattungen", Botanische Jahrbücher, 88, 70-122.

Erdtman, G. (1960). "The acetolysis methoda revised description", Sven Bot Tidskr, 54, 516-564.
Erkara, İ. P., Köse, Y. B., Osoydan, K., Yücel, E. (2012). "Pollen morphology of some endemic Turkish Centaurea L. (Asteraceae, section Phalolepis) and their taxonomic value", Plant Systematics and Evolution, 298, 1111-1117.

Ertuğrul, K., Uysal, T., Garcia-Jacas, N., Susanna, A., Garnatje, T. (2004). "The systematic position of Centaurea ensiformis and Centaurea isaurica from Turkey and the evolution of some characters in Centaurea", Israel Journal of Plant Sciences, 52, 257263.

Escher, G. B., Santos, J.S., Rosso, N.D., Marques, M.B., Azevedo, L., Do Carmo M.A.V., Daguer, H., Molognoni, L., Prado-Silva, L.D., Sant'Ana, A.S., Da Silva M.C., Granato, D. (2018). "Chemical study, antioxidant, anti-hypertensive, and cytotoxic/cytoprotective activities of Centaurea cyanus L. petals aqueous extract", Food and Chemical Toxicology, 118, 439453.

Garbacki, N., Gloaguen, V., Damas, J., Bodart, P., Tits, M., Angenot, L. (1999). "Anti-inflammatory and immunological effects of Centaurea cyanus flower-heads", Journal of Ethnopharmacology, 68, 235-241.

Haque, M., Godward, M. (1984). "New records of the carpopodium in Compositae and its taxonomic use", Botanical Journal of the Linnean Society, 89, 321-340.

İnceer, H., Bal, M., Çeter, T., Pınar, N.M. (2012). "Fruit structure of 12 Turkish endemic Tripleurospermum Sch. Bip.(Asteraceae) taxa and its taxonomic implications", Plant Systematics and Evolution, 298, 845-855.

Johansen, D.A. (1940). "Plant microtechnique" McGraw-Hill Book Company, New York.

Kaya, Z., Orcan, N., Binzet, R. (2010). "Morphological, anatomical and palynological study of Centaurea calcitrapa L. ssp. cilicica (Boiss. \& Bal.) Wagenitz and 
Centaurea solstitialis L. ssp. carneola (Boiss.) Wagenitz endemic for Turkey", Pakistan Journal of Botany, 42, 59-69.

Karanović, D., Zorić, L., Zlatković, B., Boža, P., Luković, J. (2016). "Carpological and receptacular morpho-anatomical characters of Inula, Dittrichia, Limbarda and Pulicaria species (Compositae, Inuleae): Taxonomic implications", $\quad$ Flora-Morphology, Distribution, Functional Ecology of Plants, 219, 48-61.

Kodak, E., Pınar, N. M., Adıgüzel, N., Acar, A. (2012). "Pollen morphology of some taxa of genus Tanacetum L.(Asteraceae) in Turkey", Mellifera, 12, 2-10.

Köse, Y. B., İşcan, G., Demirci, B. (2016). "Antimicrobial Activity of the Essential Oils Obtained from Flowering Aerial Parts of Centaurea lycopifolia Boiss. et Kotschy and Centaurea cheirolopha (Fenzl) Wagenitz from Turkey", Journal of Essential Oil Bearing Plants, 19, 762-768.

Kültür, Ş., Bona, M., Nath, E.Ö. (2016). “A new species of Centaurea (Asteraceae) from East Anatolia, Turkey", Phytotaxa, 247, 8591.

Mesfin, T., Crawford, D. J., Smith, E. B. (1995). "Pollen morphology of North American Coreopsis (CompositaeHeliantheae)", Grana, 34, 21-27.

Mukherjee, S.K., Nordenstam, B. (2004). "Diversity of carpopodial structure in the Asteraceae and its taxonomic significance", Comp. Newsl, 41, 29-41.

Pınar, N.M., İnceoğlu, Ö. (1996). “A comparative study on the pollen morphology of Centaurea triumfettii All. Groups. A, B and C with light and electron microscopy", Turkish Journal of Botany, 20, 395-399.
Pinar, N. M., Dönmez, E. O. (2000). "Pollen morphology of some Turkish endemic Helichrysum Gaertner species (Compositae)", Pakistan Journal of Botany, 32, 295-301.

Pınar, N.M., Coşkunçelebi, K., Şimşek, D., Okur, S., Makbul, S., Acar, A. (2016). "Pollen morphology of Scorzonera (Asteraceae) in Turkey", Phytotaxa, 252, 233-262.

Punt, W., Hoen, P. P., Blackmore, S., Nilsson, S., Thomas, Al. (2007). "Glossary of pollen and spore terminology", Review of Palaeobotany and Palynology, 143, 1-81.

Punt, W., Hoen, P. 2009. "The Northwest European Pollen Flora, 70: AsteraceaeAsteroideae", Review of Palaeobotany and Palynology, 157, 22-183.

Stix, E. (1960). "Pollenmorphologische untersuchungen an Compositen", Grana, 2, 41-104.

Skvarla, J.J., Turner, B.L., Patel, V.C., Tomb, A.S. (1977). "Pollen morphology in the Compositae and in morphologically related families", The Biology and chemistry of the Compositae, Eds: Heywood, V. H., Harborne, J. B., ve Turner, B. L., London, 141-248.

Salgado-Labouriau, M. (1982). "On cavities in spines of Compositae pollen", Grana, 21, 97-102.

Takhtajan, A. (1997). "Diversity and classification of flowering plants", Columbia University Press, New York.

Thome, R.F. (1983). "Proposed new realignments in the angiosperms", Nordic Journal of Botany, 3, 85-117. 
Uysal, I., Çelik, S., Menemen, Y. (2005). "Morphology, anatomy, ecology, pollen, and achene features of Centaurea polyclada DC. (Sect. Acrolophus) in Turkey", Journal of Biological Sciences, 5, 176-180.

Uysal, T. (2006). "Türkiye Centaurea (Asteraceae) cinsi Cheirolepis (Boiss.) O. Hoffm. seksiyonunun morfolojik, karyolojik ve moleküler revizyonu", Doktora Tezi, Selçuk Üniversitesi Fen Bilimleri Enstitüsü, Konya, 184.

Uysal, T. (2012). “Centaurea L.”, Türkiye Bitkileri Listesi (Damarlı Bitkiler). Eds: Güner, A., Aslan, S., Ekim, T., Vural, M. ve Babaç, M.T., İstanbul, Nezahat Gökyiğit Botanik Bahçesi ve Flora Araştırmaları Derneği Yayını, 127-140.

Uysal, T., Hamzaoğlu, E., Ertuğrul, K., Bozkurt, M. (2016). "A New Species of Centaurea (Asteraceae) From Turkey", Phytotaxa, 275, 149-158.

Uysal, T., Hamzaoğlu, E. (2017). “A new Centaurea L. (Asteraceae) species from Turkey", Plant Biosystems-An International Journal Dealing with all Aspects of Plant Biology, 151, 813-821.

Uysal, T., Dural, H., Tugay, O. (2017). "Centaurea sakariyaensis (Asteraceae), a new species from Turkey", Plant Biosystems - An International Journal Dealing with all Aspects of Plant Biology, 151, 126-130.

Yentür, S. (2003). "Bitki Anatomisi". İstanbul Üniversitesi Fen Fakültesi Yayını, İstanbul.

Yüzbaşığlu, S., Bona, M., Genç, İ. (2015). "A new species of Centaurea sect. Pseudoseridia

(Asteraceae) from north-eastern Turkey", Phytokeys, 53, 27-38.
Wagenitz, G. (1955). "Pollenmorphologie und Systematik in der Gattung Centaurea L. s. 1", Flora oder Allgemeine Botanische Zeitung, 142, 213-279.

Wagenitz, G. (1976). "Systematics and phylogeny of the Compositae (Asteraceae)", Plant Systematics and Evolution, 125, 29-46.

Wodehouse, R.P. (1935). "Pollen grains", Mcgraw-Hill Book Company, New York, London. 